\title{
Petroleum Coke Particle Size Effects on the Treatment of EAF Dust through Microwave Heating
}

\author{
Xiang Sun, Jiann-Yang Hwang*, Xiaodi Huang, and Bowen Li \\ Department of Materials Science and Engineering \\ Michigan Technological University, MI 49931 \\ *Corresponding Author, contact: jhwang@mtu.edu \\ Phone: 906-487-2600, Fax: 906-487-2934
}

\begin{abstract}
EAF dusts were mixed with petroleum coke and irradiated together under microwave for a pyrometallurgical treatment. It was found that particle size of the reducing agent played an important role in affecting the reduction degree. Both zinc removal and metallization degree increased with the decreasing of the coke particle size. By changing both microwave time and carbon addition, optimal zinc removal at $99.23 \%$ and metallization at $100 \%$ can be achieved with 15 minutes microwave irradiation and $20 \mathrm{wt} \%$ carbon addition.
\end{abstract}

Key Words: EAF dust, microwave processing, zinc recovery, metal extraction

\section{INTRODUCTION}

EAF (electric arc furnace) dust is formed under minimill steelmaking operations due to the high processing temperature (around $1600{ }^{\circ} \mathrm{C}$ ). Certain metals such as $\mathrm{Zn}, \mathrm{Pb}, \mathrm{Cd}, \mathrm{Na}, \mathrm{Mn}$ and $\mathrm{Fe}$ are volatilized and oxidized, then condensed or mechanically carried over and finally collected as appeared as dust form. Because it contains water leachable heavy metals such as lead, chromium and cadmium, EAF dust was categorized as hazardous waste K061 under EPA regulation in 1980 [1]. Management of EAF dust becomes a major economic problem in US minimill steelmakers due to the environmental concern. Several technologies have been developed and some of them have been constructed in commercial scale. So far most processes are concerned 
with pyrometallurgical and hydrometallurgical ways to recover valuable metals such as zinc or iron. However, both technical and economical problems are still remaining.

Microwave interacts with materials at molecule level and heat can be generated inside materials. The energy consumption and process time can be highly reduced. Due to the great and unique advantages, microwave has been applied to numerous industries and still attracts lots of research interests [2-4]. Microwave treatment of EAF dust has also been studied and zinc removal from the hazardous waste has been proved feasible [5-6].

In metal extraction, the carbon reducing agent plays an important role. Carbon particle size is usually the major concern. In microwave heating, the carbon is directly interacting with the electromagnetic waves. Carbons at different particle sizes may have various heating consequences thus leading to different extraction results. This is not common when conventional heating methods are utilized. Moreover, in order to utilize such advanced technique into real industry, inexpensive reductant is a critical factor to reduce the total cost. Petroleum coke is an inexpensive carbon source, thus it could be an ideal reductant source for industrialization of microwave metal extraction. Therefore, a study on the coke particle size effects in microwave treatment of EAF dust is required.

This paper presents a laboratory investigation of processing EAF dust through microwave heating, with focus on the carbon particle size effects on the reduction degree and associated results.

\section{EXPERIMENTAL}

\subsection{Experimental System}

Experiments were conducted in a modified microwave oven. The details of setup have been described in our previous publication [6]. EAF dusts were mechanically mixed with petroleum cokes, and then put into a microwave transparent clay crucible. A crucible holder with a pipe connected was used to rivet the crucible and direct the outgoing gases or particles. A glass funnel was loosely put right on top of the pipe and connected to the particle collector. A paper filter which has a pore size of $2.5 \mu \mathrm{m}$ was fixed inside the collector and used to hold up the solidified particles. The metal or compound vapors from the crucible are sucked by a pump, solidified, and trapped in the collector.

\subsection{Characterizations}

Inductively coupled plasma (ICP) was utilized to determine the chemical compositions. The dissolution of all the elements was conducted by using combination of $\mathrm{HCl}$ and $\mathrm{HNO}_{3}$ acids. 
Metallic iron was determined by ICP after dissolving samples in $0.5 \mathrm{~N} \mathrm{CuSO}_{4}$ solutions instead of acid mixtures [7] based on the following reaction:

$$
\mathrm{Fe}+\mathrm{CuSO}_{4} \rightarrow \mathrm{FeSO}_{4}+\mathrm{Cu}
$$

The solution was heated until boiling for 30 minutes on a hot plate. Continuous stirring is necessary in order to prevent reduced copper precipitates to form a $\mathrm{Cu}$ thin film around the metallic iron particles which may prevent these particles from further oxidation. The later solution was filtered and diluted, then analyzed by ICP.

Elemental analyzer NA1500 (Fisons Instruments Inc) were used to determine the total carbon contents. The phase compositions were determined by getting X-ray diffraction (XRD) patterns on a Scintag XDS2000 powder diffractometer with a graphite monochromoter using $\mathrm{Cu} \mathrm{K} \alpha$ radiation. Scanning electron microscope (SEM) JEOL JSM-6400 with EDS analyzer was utilized to study morphology and microstructures.

Processing temperature was determined by using shielded thermocouples. However, there are studies [8-9] showing that with present of thermocouple in microwave field, the local distribution of electromagnetic field can be highly distorted and abruptly changed. This may lead inaccurate reading and processing problems such as local breakdown or thermal runaway. Therefore, in this study, we measured the temperature by immediately inserting the thermocouple into the sample right after the time up of the microwave power. The heat loss to the surroundings was slowed by the refractory, so obtained temperature is not too far from the real number.

\subsection{Raw Materials}

Petroleum coke is utilized as the carbon source for this study. Since it is a by-product from the petroleum refineries, it is a very inexpensive material. Samples from Mid-Continent Coal and Coke Co. were obtained for this study. Table 1 shows the composition of the material. It has $92.6 \mathrm{wt} \%$ carbon and $6.7 \%$ of sulfur and tiny amount of iron, vanadium, nickel, etc. The sample was grounded and sequentially screened to +16, 16-40, 40-60, 60-100, 100-140, 140-200, 200270, and -325 meshes. Carbon addition was calculated by carbon percentage.

Table 1 Chemistry of obtained petroleum coke

\begin{tabular}{lllllllll}
\hline $\begin{array}{l}\text { Carbon } \\
(\mathrm{wt} \%)\end{array}$ & $\begin{array}{l}\text { Sulfur } \\
(\mathrm{wt} \%)\end{array}$ & $\begin{array}{l}\text { Ash } \\
(\mathrm{wt} \%)\end{array}$ & $\begin{array}{l}\mathrm{Fe} \\
(\mathrm{ppm})\end{array}$ & $\begin{array}{l}\mathrm{V} \\
(\mathrm{ppm})\end{array}$ & $\begin{array}{l}\mathrm{Si} \\
(\mathrm{ppm})\end{array}$ & $\begin{array}{l}\mathrm{Ca} \\
(\mathrm{ppm})\end{array}$ & $\begin{array}{l}\mathrm{Na} \\
(\mathrm{ppm})\end{array}$ & $\begin{array}{l}\mathrm{Ni} \\
(\mathrm{ppm})\end{array}$ \\
\hline 92.6 & 6.7 & 0.61 & 1323 & 1347 & 227 & 110 & 93 & 307 \\
\hline
\end{tabular}


Raw EAF dusts were received from Steel Dynamics, Inc. The X-ray diffraction pattern, as in Figure 1, showed the major phases in the dust are $\mathrm{ZnFe}_{2} \mathrm{O}_{4}$ (Franklinite), $\mathrm{ZnO}$ (Zincite) and $\mathrm{KCl}$ (Sylvite). It also presents that most of zinc and iron are in oxides form.

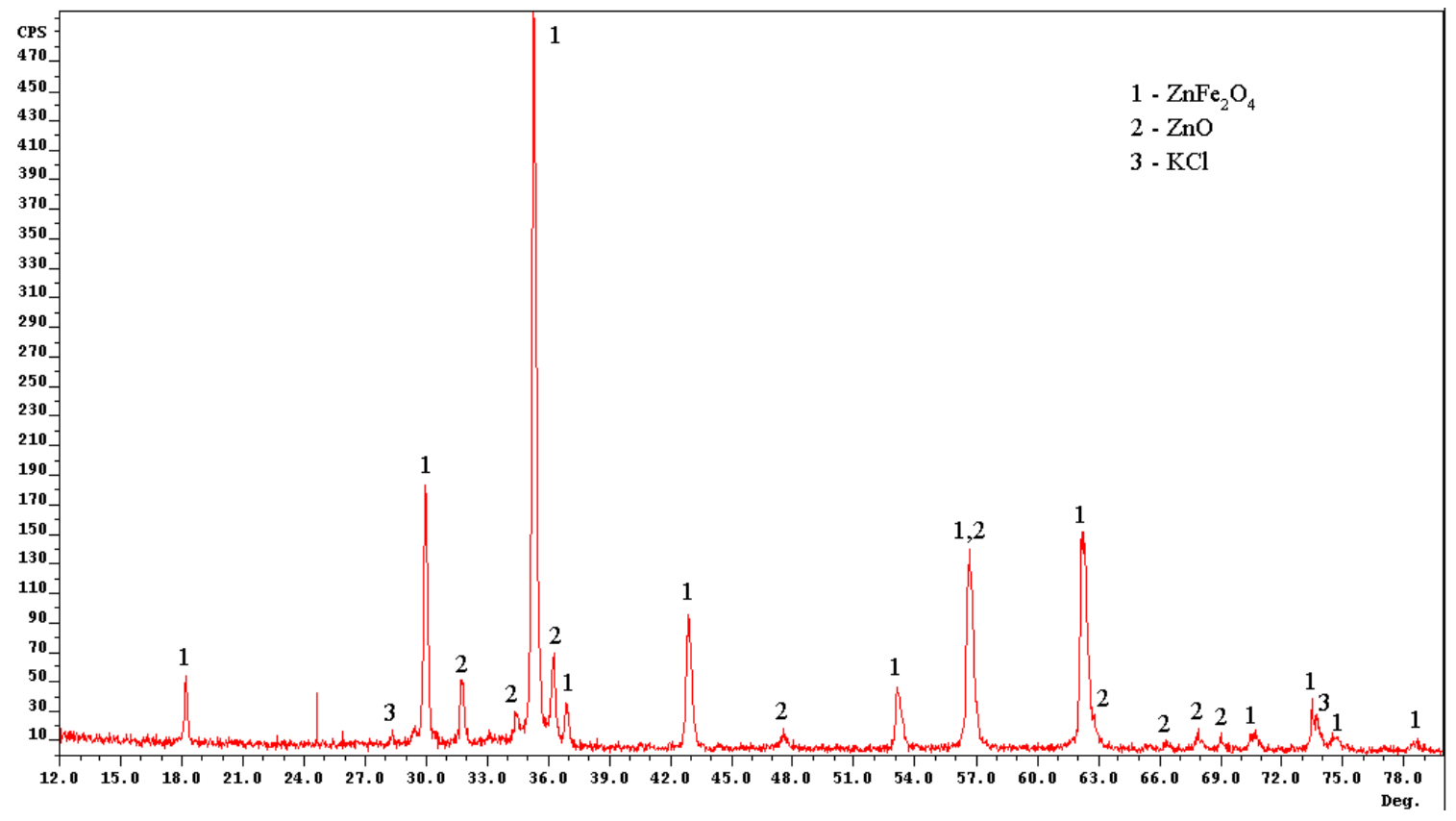

Figure 1 XRD pattern of EAF dust

The morphology of the EAF dust was observed from SEM analysis. As shown in Figure 2, the dust generally contains very tiny (less than $2 \mu \mathrm{m}$ ) spheroids, some of which agglomerate into relative large particles $(10-100 \mu \mathrm{m})$. Figure 2(a) and (b) illustrate composition variations of particles in different sizes. The small particles mainly consist of $\mathrm{ZnFe}_{2} \mathrm{O}_{4}$ and $\mathrm{Fe}_{3} \mathrm{O}_{4}$, which fill about $80-90 \%$ of the whole dusts. Medium size particles are metal oxides or silicates. The big particles are mostly Fe-enriched silicates or oxides and there are fine oxides particles attached on them. In general, EAF dust contains mainly of $\mathrm{ZnFe}_{2} \mathrm{O}_{4}, \mathrm{Fe}_{3} \mathrm{O}_{4}, \mathrm{FeO}, \mathrm{ZnO}$, minor amount $\mathrm{KCl}$, Fe-Al-Ca-Zn-Mg oxides, and trace amount of $\mathrm{Fe}_{2} \mathrm{O}_{3}$ and various silicates. However, nearly none of these compounds was found to be pure in composition. Element substitution for each other is common in these compounds [10]. For example, in a typical $\mathrm{ZnFe}_{2} \mathrm{O}_{4}$ particle, $1.33 \% \mathrm{Ca}, 1.2 \%$ $\mathrm{Mg}, 1.78 \% \mathrm{Mn}$ was observed to substitute for $\mathrm{Zn}$ and Fe. These substitutions indicate the complexity of the dust compositions.

\section{RESULTS AND DISCUSSION}

The carbon-dust mixtures were irradiated by microwave so that heats were generated inside the materials and a homogeneous heating was expected. When the temperature was favorable, gasification of carbons and carbon monoxide began to occur and sequentially reduction of 
compounds in the dust got started. At even higher temperature, reduced metallic zinc would vaporize out.
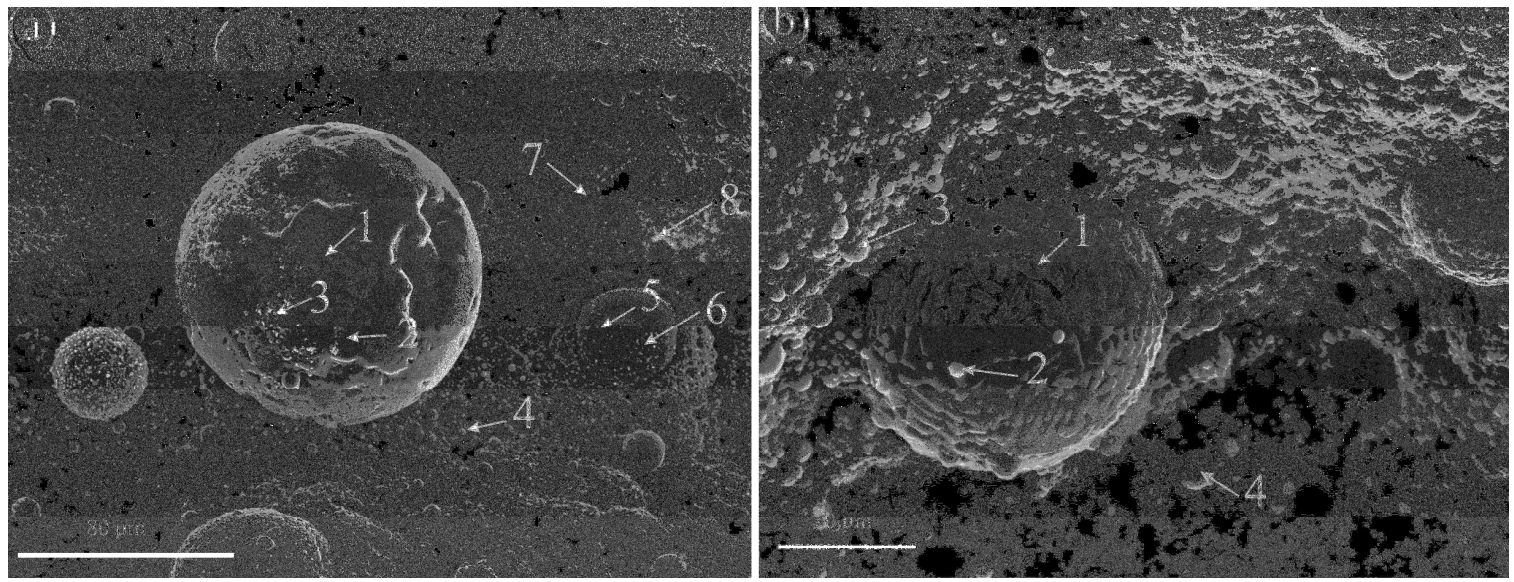

Figure 2 General morphology of EAF dust

(a) 1, 2 - Fe-Ca-Mg oxides, 3 - Ca-Fe-Zn oxides, 4 - $\mathrm{ZnFe}_{2} \mathrm{O}_{4}, 5$ - FeO, 6 - Fe-Ca silicates, 7 $\mathrm{Fe}-\mathrm{Ca}$ oxides, $8-\mathrm{CaO}$

(b) $1-\mathrm{ZnFe}_{2} \mathrm{O}_{4}, 2-\mathrm{Fe}_{2} \mathrm{O}_{3}, 3-\mathrm{Fe}_{3} \mathrm{O}_{4}, 4-\mathrm{Fe}-\mathrm{Zn}$-Al silicates, 5 - metallic $\mathrm{Fe}$

Here, our concerns are focused on iron and zinc since they are the most abundant valuable elements in the dust. An idea outcome from the process is the perfect extraction and separation of $\mathrm{Fe}$ and $\mathrm{Zn}$. The metallization degree and zinc removal are calculated by following equations:

$$
\begin{aligned}
& \text { Metallization }=\frac{W_{F E}}{W_{F E \text { tatal }}} \times 100 \% \\
& Z \text { inc removal }=\frac{W_{Z n}}{W_{Z n \text { tatal }}} \times 100 \%
\end{aligned}
$$

Where, $W_{F,}$ is the weight of metallic iron and $W_{F e t o t a l}$ is the total iron content in the final product; $W_{z n}$ is the weight of total zinc in the product and $W_{z n \text { total }}$ is the total zinc content in the original dust.

\subsection{Carbon Size Effects}

To study the carbon size effects, each test was performed under the same carbon addition (15 wt $\%)$, microwave power $(1.1 \mathrm{~kW})$ and microwave time $(15 \mathrm{~min})$. The results of zinc removal and iron reduction degree (metallization) are shown in Figure 3. The zinc removal and metallization degrees both increased with decreasing of petroleum coke particle size. At coke particle size less than $44 \mu \mathrm{m}$ (-325 mesh), zinc removal and metallization reached the highest degree, which were $92.73 \%$ and $99.59 \%$, respectively. 


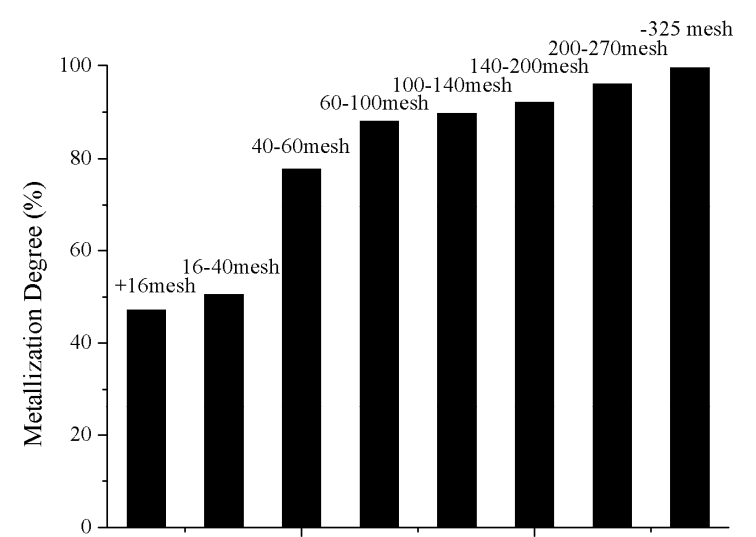

Coke Particle Size

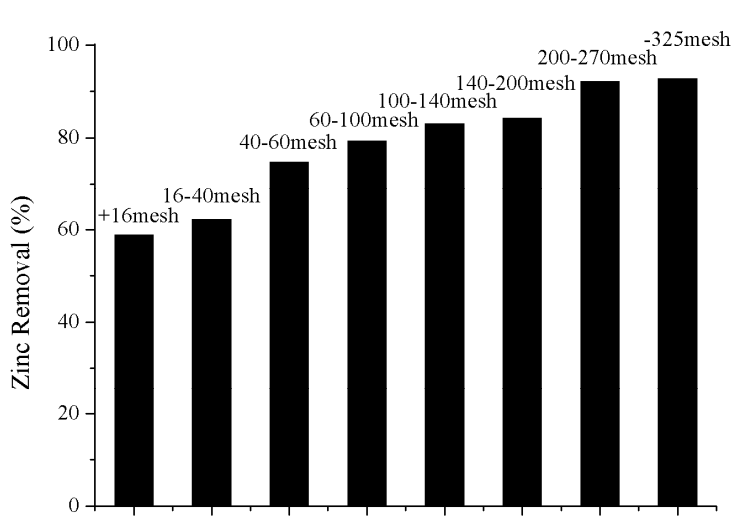

Coke Particle Size

Figure 3 Effects of petroleum coke size on the zinc removal (left) and metallization degrees (right), MW power $1.1 \mathrm{~kW}$, processing time $15 \mathrm{~min}$, coke addition $15 \mathrm{wt} \%$

The original dusts have most particles smaller than $2 \mu \mathrm{m}$. As the coke particle size went smaller, the surface areas for chemical reactions became larger. This is believed as a major cause for the better reduction degree at finer coke particle size.

On the other hand, heat conduction may be another important issue. Table 2 shows the sample temperature of EAF dust and petroleum coke particles at various sizes after being radiated by microwave for 5 minutes. EAF dust couples with microwave very well and can be heated very fast due to the presence of $\mathrm{ZnFeO} 4$, which is a magnetic oxide [11]. However, petroleum coke is not a good microwave absorber and even for smaller particle size, the absorption doesn't have any significant improvement. When the mixture was heated by microwave, EAF dust absorbed most of the energy and coke got temperature increase by heat conduction from the dust. Smaller particles have larger contact areas for heat conduction which can cause faster gasification of carbon. This is obvious from the results of residual carbon analysis. Such observation is unique for petroleum coke since graphite and coke have much better interaction with microwave [6]. Therefore, in order to use inexpensive carbon source for treatment of EAF dust, smaller coke particles should be used to have good treatment outcome.

Table 2 Temperature after 5 min microwave heating (20 g sample, power $1.1 \mathrm{~kW}$ )

\begin{tabular}{ccccc}
\hline EAF dust & $\begin{array}{c}+16 \text { mesh } \\
\text { pet coke }\end{array}$ & $\begin{array}{c}40-60 \text { mesh } \\
\text { pet coke }\end{array}$ & $\begin{array}{c}140-200 \text { mesh } \\
\text { pet coke }\end{array}$ & $\begin{array}{c}-325 \text { mesh } \\
\text { pet coke }\end{array}$ \\
\hline $907{ }^{\circ} \mathrm{C}$ & $231{ }^{\circ} \mathrm{C}$ & $232{ }^{\circ} \mathrm{C}$ & $202{ }^{\circ} \mathrm{C}$ & $221{ }^{\circ} \mathrm{C}$ \\
\hline
\end{tabular}

From Table 3, there are significant amount of unburned carbon left for bigger coke particles after processing. And the percentage of carbon left decreased with the decreasing of carbon size. So 
both larger reaction area and better heat transfer contributed to the optimum removal and metallization for the smallest particle size of carbon.

Table 3 Residual carbon after processing (wt \%)

\begin{tabular}{cccccccc}
\hline+16 mesh & $\begin{array}{c}16-40 \\
\text { mesh }\end{array}$ & $\begin{array}{c}40-60 \\
\text { mesh }\end{array}$ & $\begin{array}{c}60-100 \\
\text { mesh }\end{array}$ & $\begin{array}{c}100-140 \\
\text { mesh }\end{array}$ & $\begin{array}{c}140-200 \\
\text { mesh }\end{array}$ & $\begin{array}{c}200-270 \\
\text { mesh }\end{array}$ & $\begin{array}{c}-325 \\
\text { mesh }\end{array}$ \\
\hline 7.4 & 6.3 & 2.4 & 1.6 & $<1$ & $<1$ & $<1$ & $<1$ \\
\hline
\end{tabular}

Figure 4 shows some XRD patterns of the reduced solids in the crucible. The residuals contain $\mathrm{Fe}$ in majority, minor amount of $\mathrm{FeO}, \mathrm{ZnS}, \mathrm{KCl}$, and $\mathrm{Ca}_{3} \mathrm{Mg}\left(\mathrm{SiO}_{4}\right)_{2}$, and trace amount of $\mathrm{ZnFe}_{2} \mathrm{O}_{4}$. As the coke size decreased, the $\mathrm{FeO}$ peak is diminishing, which proves the better metallization degree. The amorphous carbon left in the +16 mesh and 16-40 mesh fractions indicates the existence of significant amount of unburned coke in the coarse fractions. Also significant $\mathrm{ZnO}$ and $\mathrm{ZnS}$ peaks were found in mixtures of big particles of carbon. Petroleum coke is rich $(6.7 \mathrm{wt} \%)$ in sulfur. So it is not surprised to see $\mathrm{ZnS}$ compounds formed. However, as the particle sizes became smaller, peaks of these zinc compounds diminished. When the reaction chamber is under a non-reducing atmosphere, as what happens in samples with bigger coke particles, fewer $\mathrm{ZnO}$ could be reduced and also part of the reduced $\mathrm{Zn}$ could be reoxidized. Calcium and magnesium silicates were observed to be the most abundant slag phases.

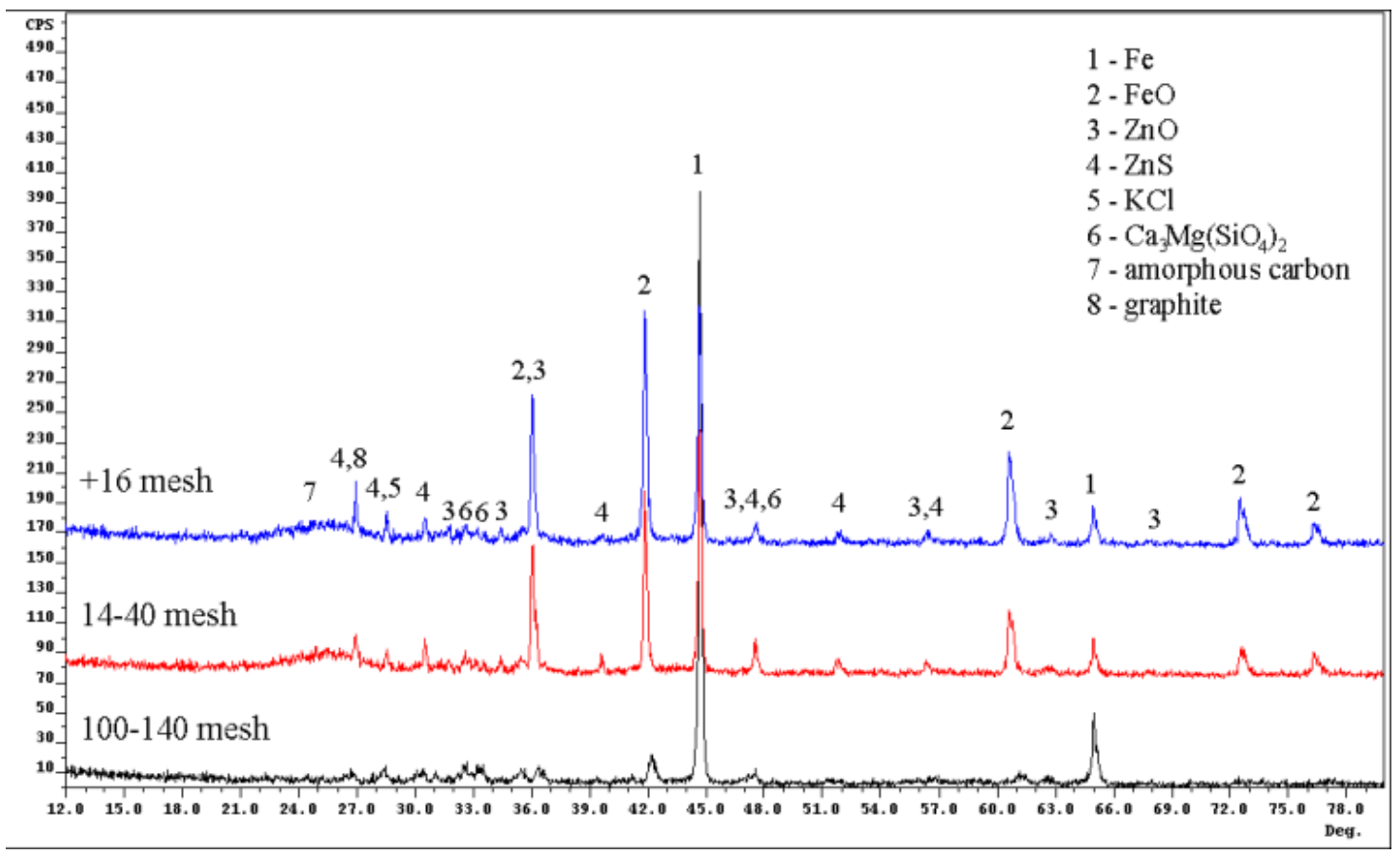

Figure 4 XRD patterns of the reduced mixtures at different carbon sizes 


\subsection{Processing Time and Carbon Addition Effects}

Even though almost 100\% metallization degree was achieved at the smallest coke size, there was still significant percentage of zinc residual in the products, which showed that the carbon for reduction is not enough. So carbon additions (coke size -325 mesh) as well as microwave time were varied to study the effects.

As shown in Figure 5, the reduction degrees for both zinc and iron improved consistently with the increasing of microwave processing time and carbon addition. The reduction degree of iron is always higher than that of zinc, which indicates the faster reaction rates for iron oxides than zinc oxides. Iron oxides have very good absorption of microwave and can be heated up rapidly. However, zinc oxides are very poor microwave absorbers [12]. In the processing, iron oxides absorbed most of the microwave energy, thus the reduction of the iron oxides were favored. Part of zinc in the ferrites is reduced together with iron. But the zinc in its own oxide and sulfide forms is reduced at lower rate. Near complete removal of zinc and reduction of iron oxides can be achieved at $20 \mathrm{wt} \%$ carbon addition and 15 minutes microwave time.

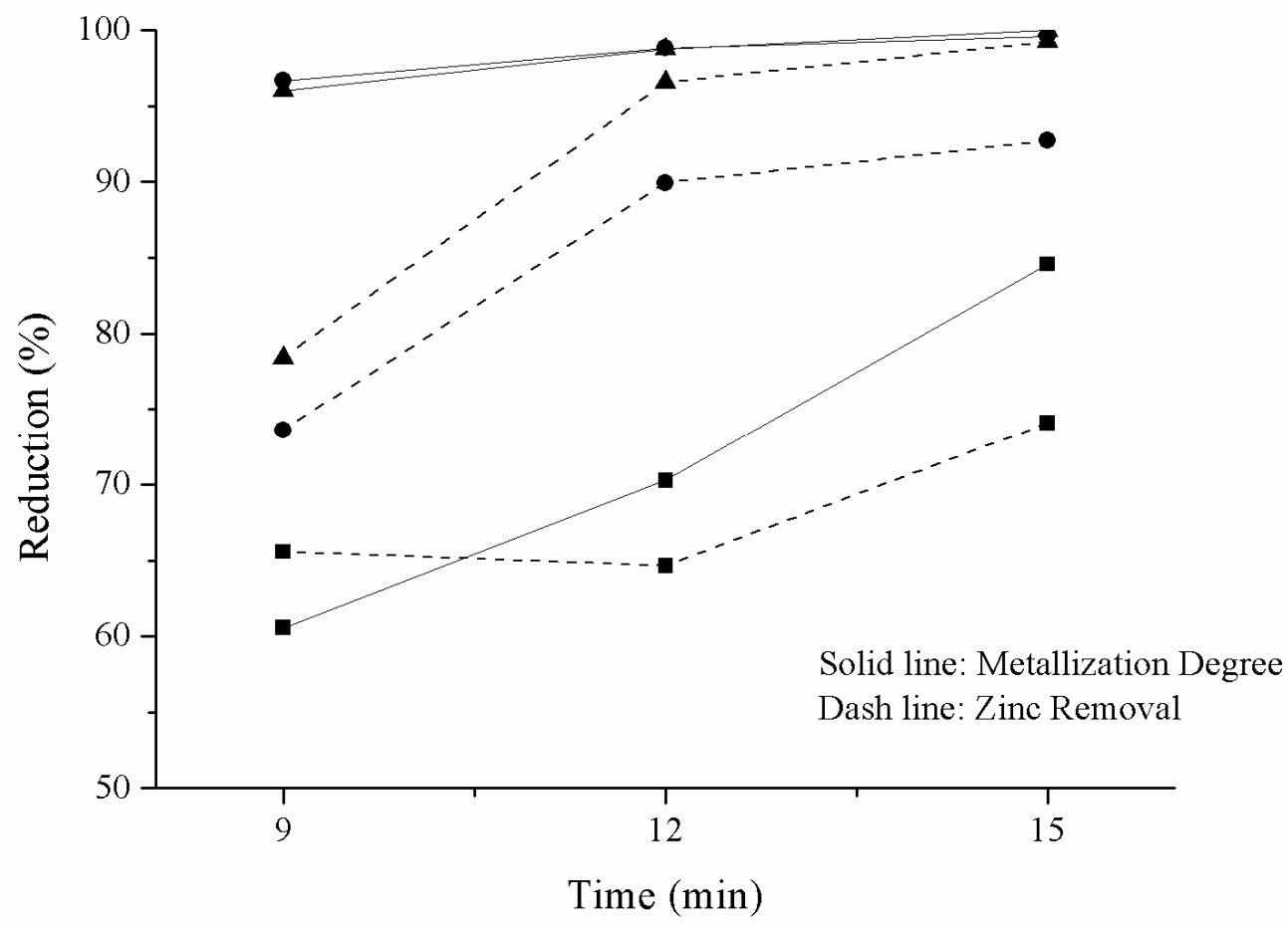

Figure 5 Zinc removal and metallization degree as a function of microwave time and carbon addition $(\mathbf{\bullet}) 10 \mathrm{wt} \%,(\bullet) 15 \mathrm{wt} \%(\boldsymbol{\Lambda}) 20 \mathrm{wt} \%$, microwave power $1.1 \mathrm{~kW}$ 


\subsection{Products}

Two kinds of products have been obtained. One is the iron rich residual in the crucible, and the other is the collected particles.

A chemical analysis of the iron rich residual from the $20 \%$ carbon addition and 15 minutes microwave radiation run is shown in Table 4 . The residue contains $69.5 \%$ metallic iron, $69.8 \%$ total iron, $5.5 \%$ calcium, $2.9 \%$ manganese, $2.9 \%$ magnesium, and less than $0.5 \%$ of zinc, chromium, lead, copper, sodium. Apparently, metallization of iron is near $100 \%$.

Table 4 Typical chemical analysis of iron rich residue (20 wt \% carbon addition, MW 15min)

\begin{tabular}{cccccccc}
\hline Element & $\mathrm{Fe}(\mathrm{M})$ & $\mathrm{Fe}(\mathrm{T})$ & $\mathrm{Zn}$ & $\mathrm{Cr}$ & $\mathrm{Ni}$ & $\mathrm{Cd}$ & \\
\hline $\mathrm{Wt} \%$ & 69.49 & 69.84 & 0.138 & 0.29 & 0.084 & $<0.01$ & \\
\hline Element & $\mathrm{Pb}$ & $\mathrm{Si}$ & $\mathrm{Mn}$ & $\mathrm{Mg}$ & $\mathrm{Cu}$ & $\mathrm{Ca}$ & $\mathrm{Na}$ \\
\hline $\mathrm{Wt} \%$ & 0.129 & 0.997 & 2.839 & 2.898 & 0.237 & 5.533 & 0.44 \\
\hline
\end{tabular}

SEM pictures show the morphology of the residuals. As in Figure 6, metallic iron is the major phase and small particles agglomerated together forming big spheroids. About 2-3 at\% Mn has been found in most metallic iron particles. The residual mixture also contains minor amount of $\mathrm{Ca}-\mathrm{Mg}$ silicates, trace amount of carbides, sulfides and unburned carbon. The silicate rich slag is surrounding the iron particles and the separation between them is obvious. Some molten phases have formed and the residue has partly sintered.

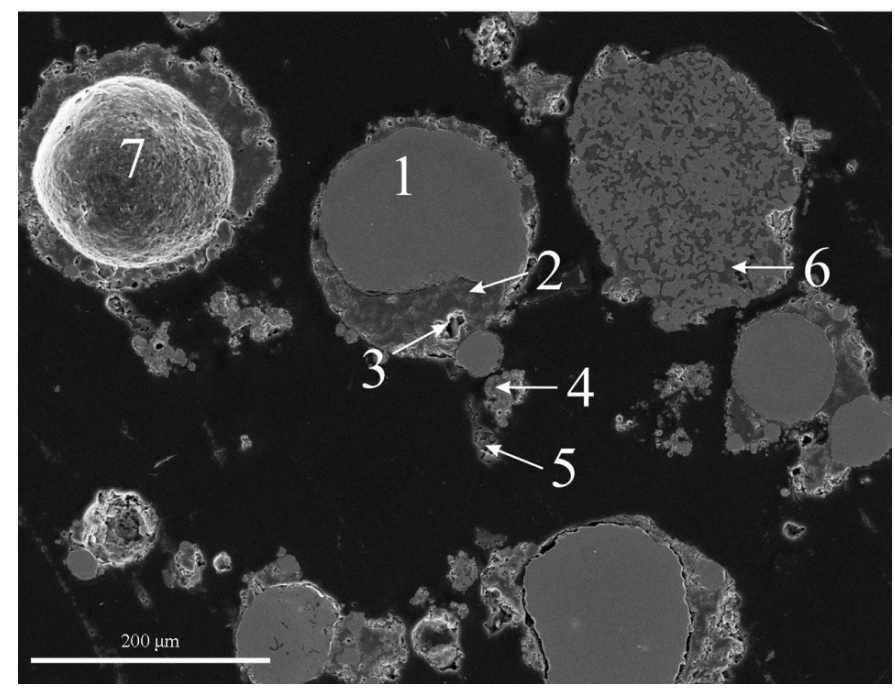

Figure 6 SEM picture of residual mixture (carbon addition $15 \mathrm{wt} \%$, MW 15min) 1 - metallic Fe, 2 - Mg-Ca silicates, 3 - $\mathrm{Ca}_{3} \mathrm{Mg}\left(\mathrm{SiO}_{4}\right)_{2}, 4-\mathrm{CaS}, 5$ - residual carbon, 6 - $\mathrm{Ca}-\mathrm{Al}$ silicates, 7 - Mg-Ca silicates and sulfides 
A XRD pattern (Figure 7) of the collected particles presented that the most abundant phase is metallic zinc. $\mathrm{KCl}, \mathrm{CrCl}_{2}$ and metallic $\mathrm{Pb}$ are in minor amount. Very small peak of $\mathrm{ZnO}$ is also present.

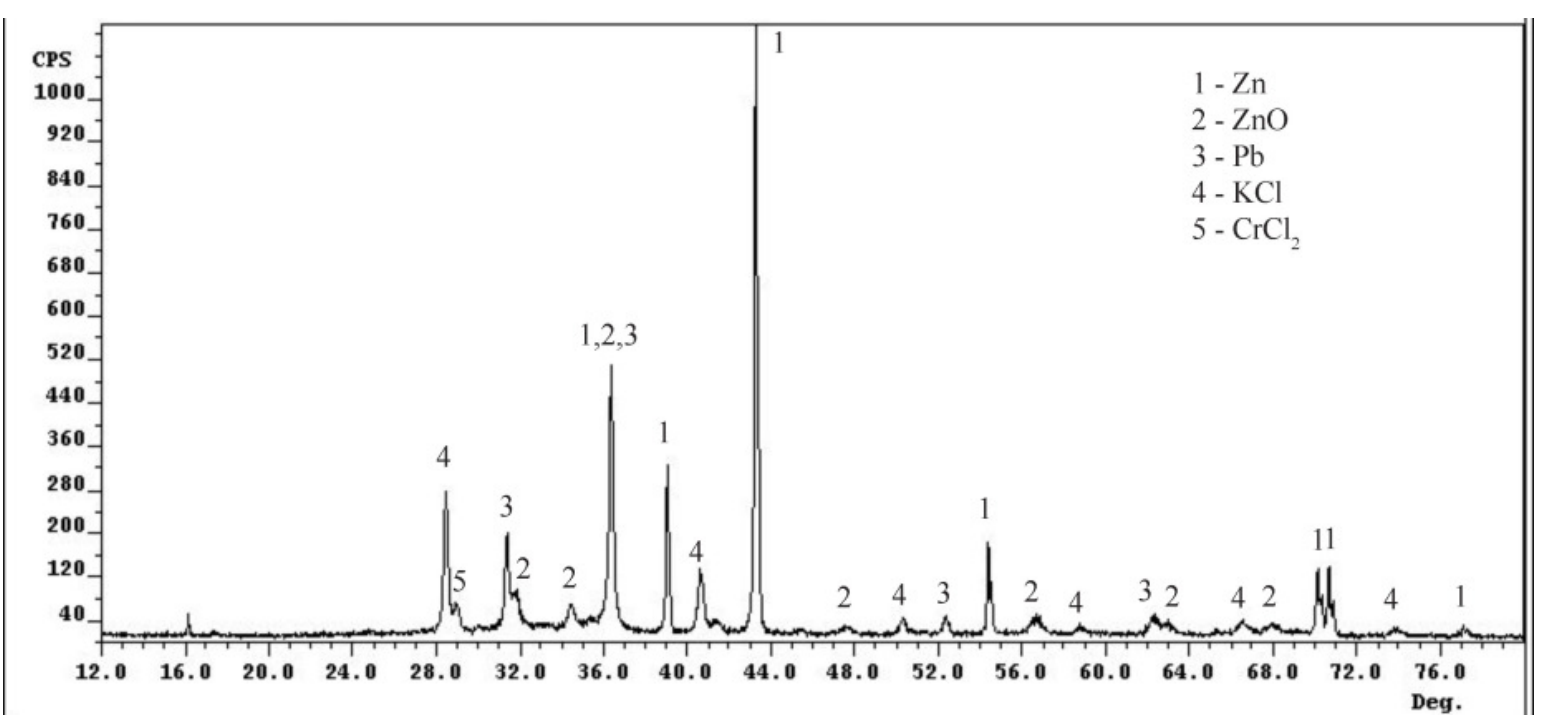

Figure $7 \mathrm{XRD}$ analysis of the collected particles

\section{CONCLUSION}

Microwave has been tested for processing of electric arc furnace dusts in laboratory scale. Particle size of reducing agent has potential effects on the reduction degrees. Both zinc removal and metallization degrees have been found to increase with decreasing of the petroleum coke particle size. Also by changing the microwave time and fixed carbon addition, optimal yield has been achieved. $99.23 \%$ zinc removal and $100 \%$ metallization have been obtained at 15 minutes microwave time and $20 \mathrm{wt} \%$ carbon addition. Two kinds of products, an iron rich residual in the crucible and a metallic zinc rich product containing particles collected from condensed vapors have shown the excellent separation and potential recycling possibility.

\section{ACKNOWLEDGEMENTS}

The authors would like to thank Steel Dynamics, Inc. for providing dust samples and Kaikun Yang for SEM analyses.

\section{REFERENCES}

[1] Sofilić, T., Rastovčan-Mioč, A., Cerjan-Stefanović, Š., Novosel-Radović, V., and Jenko, M., 2004, "Characterization of steel mill electric-arc furnace dust." J. Hazard. Mater., Vol. 109, pp. 59-70. 
[2] Hwang, J.Y., and Huang, X., Advanced Processing of Metals and Materials, Volume 5-New, Improved and Existing Technologies: Iron and Steel and Recycling and Waste Treatment, ed. F. Kongoli and R.G. Reddy (Warrendale, PA: TMS, 2006), "New Steel Production Technology with Microwave and Electric Arc Heating." pp. 251-261.

[3] Clark, D. E., Folz, D. C., and West, J. K., 2000, "Processing materials with microwave energy.” Mater. Sci. Eng., A, Vol. 287, pp. 153-158.

[4] Shi, S., and Hwang, J. Y., 2003, "Microwave-assisted wet chemical synthesis: advantages, significance, and steps to industrialization." J. Miner. Mater. Character. Eng., Vol. 2, pp. 101-110.

[5] Ghoreshy, M., and Pickles, C.A., 1995, "Microwave processing of electric arc furnace dust." Electr. Furn. Conf. Proc., Vol. 52, pp. 187-196.

[6] Sun X., Hwang, J. Y., and Huang X., 2008, "The microwave processing of electric arc furnace dust." JOM, Vol. 60, pp. 35-39.

[7] Xu, Z., Hwang, J. Y., Greenlund, R., Huang, X., Luo, J., and Anschuetz, S., 2003, "Quantitative determination of metallic iron content in steel-making slag." J. Miner. Mater. Character. Eng., Vol. 2, pp. 65-70.

[8] Thompson, K., Booske, J. H., Cooper, R. F., Gianchandani, Y. B., and Ge, S., 2001, "Temperature measurement in microwave-heated silicon wafers." Ceram. Trans., Vol. 111, pp. 391-398.

[9] Pert, E., Carmel, et al., 2001, “Temperature Measurements during Microwave Processing: The Significance of Thermocouple Effects.” J. Am. Ceram. Soc., Vol. 84, pp. 1981-1986.

[10] Chen, T. T., Dutrizac, J. E., and Owens, D. R., 1998, "Mineralogical characterization of EAF dusts from plain carbon steel and stainless steel operations." Waste Process. Recycl. III, pp. 511-525.

[11] Rogers A., and Alexander, J., 1920, Industrial Chemistry, $3^{\text {rd }}$ ed., D. Van Nostrand, New York.

[12] Saidi, A., and Azari, K., 2005, "Carbothermic reduction of zinc oxide concentrate by microwave.” J. Mater. Sci. Technol., Vol. 21, pp. 724-728. 